\title{
Lung Lymphoepithelioma-Like Carcinoma
}

National Cancer Institute

\section{Source}

National Cancer Institute. Lung Lymphoepithelioma-Like Carcinoma. NCI Thesaurus.

Code C45519.

A rare and distinctive type of lung carcinoma characterized by the presence of a syncytial growth pattern, large vesicular nuclei with eosinophilic nucleoli, and dense lymphoplasmacytic infiltration. 